\title{
Experimental-numerical Technique to Evaluate the Thickness of TiN Thin Film
}

\author{
Avelino Manuel da Silva Dias ${ }^{a *}{ }^{\circledR}$, Everton Carneiro da Silva ${ }^{\circledR}$, Maxwell Santana Libório ${ }^{a}$ \\ ${ }^{a}$ Departamento de Engenharia Mecânica, Universidade Federal do Rio Grande do Norte (UFRN), \\ Natal, RN, Brasil.
}

Received: April 16, 2018; Revised: June 23, 2019; Accepted: July 17, 2019

In this study, the numerical analysis of instrumented indentation testing was combined with the experimental procedure to evaluate the mechanical properties and thickness of a titanium nitride ( $\mathrm{TiN}$ ) film deposited on titanium substrate $(T i)$ by plasma processing. TiN film thickness is an important parameter for the surface treatment industry. In numerical analysis, the finite elements method (FEM) was applied using Marc ${ }^{\mathrm{TM}}$ commercial software. Initially, the mechanical properties of the film and substrate were determined using a numerical-experimental methodology, combining the results of indentation testing with a Berkovich indenter and the same numerical simulation for both the film and substrate. Next, the behavior of instrumented Vickers hardness as a function of maximum indenter penetration depth $\left(h_{\max }\right)$ was compared with the numerical results of this hardness as a function of the ratio between penetration depth and film thickness $\left(h_{\max } / t\right)$. Both curves were fitted using power law equations, which calculated film thickness applying a new convergence algorithm. Finally, it also was shown that the film thickness obtained agrees with the experimental range reported in the literature.

Keywords: Experimental-numerical analysis, TiN film, indentation testing, film thickness, FEM.

\section{Introduction}

Over the past few decades, instrumented indentation testing has become a technique capable of assessing mechanical properties such as surface hardness $(H)$, Young's modulus $(E)$ and, more recently, the mechanical stress behavior curve as a function of the strain of different materials, especially thin films. ${ }^{1-9}$ However, implementing this technique to assess mechanical properties and results continues to divide the scientific community. These doubts are more significant with respect to assessing the mechanical behavior of thin films applied to metallic substrates. Due to these limitations, the use of a numerical tool capable of simulating indentation load, stress and strain behavior during the indentation cycle may result in a more reliable interpretation of these tests. For this reason, numerous studies have been conducted using discrete models to study the behavior of different classes of materials by applying the indentation test, mainly to obtain mechanical properties. ${ }^{10-19}$

Systems composed of thin films produced by plasma nitrating have been widely used in industry to improve the mechanical and tribological properties of materials such as titanium nitride deposited on titanium (TiN/Ti) substrate. According to the literature, the thickness of TiN film deposited by plasma processing on titanium substrate depends on several factors, including temperature, deposition time, controlled atmosphere, etc. In order words, depending on plasma processing, these systems (TiN/Ti) exhibit different thicknesses and, consequently, different surface hardness. ${ }^{20-21}$ In 2009 , Godoy et al studied the behavior of this surface hardness as a function of indentation load in four different samples: steel, a system composed of plasma-nitride steel, a system consisting of chromium nitride $(\mathrm{CrN})$ film deposited on steel substrate and a duplex system composed of $\mathrm{CrN}$ film deposited on plasma-nitride steel substrate (Figure 1).

a

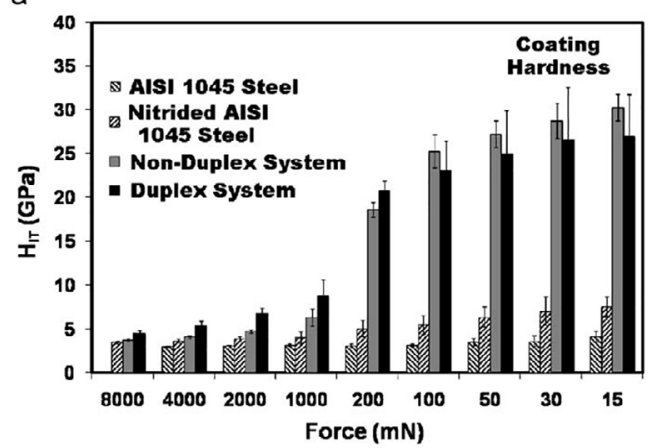

b

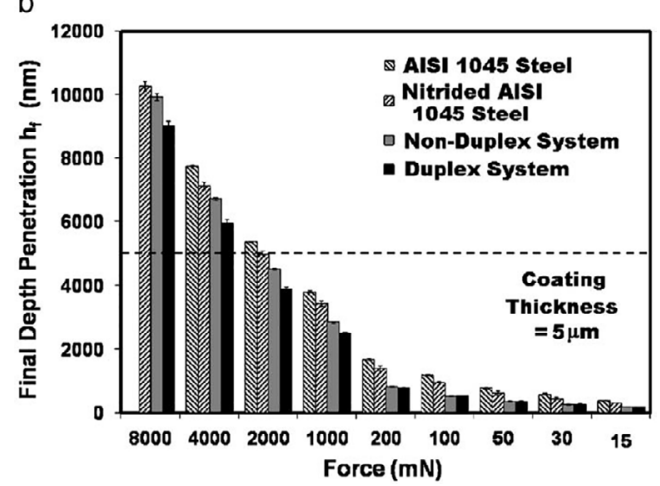

Figure 1. (a) Hardness and (b) final penetration depth data from nanoindentation measurements carried out as a function of applied force. ${ }^{22}$ 
These authors also found that hardness was obtained at low penetration depths solely for the film.2 ${ }^{22}$ On the other hand, for high penetration depths, hardness in a film/substrate system was similar only for substrate. In other words, in the aforementioned system, the effects of its mechanical properties tend to establish a relationship between maximum penetration depth $\left(h_{\max }\right)$ and film thickness $(t) .^{6-7,19-20,22-24}$

The present study applied the finite elements method $(F E M)$ in order to assess the indentation test in a system composed of TiN film deposited on titanium substrate. These simulations, aimed at assessing TiN film thickness by simulating Vickers indentation testing, combining numerical analysis and the experimental behavior of the hardness curve as a function of indentation depth, allowed us to meet our objective. In order to make this new numerical-experimental methodology viable, the procedure developed by Dias and Godoy (2010), which involves a number of Berkovich indentation tests, followed by a numerical methodology, was used to determine the mechanical properties of the film/ substrate system $(\mathrm{TiN} / \mathrm{Ti})$ under study. ${ }^{4}$ Once these properties were obtained, a new numerical algorithm was developed to determine the thickness of the film.

\section{Materials and Methods}

Numerical analysis was conducted using commercial Finite Elements software (Marc $\left.{ }^{\text {TM }} 2017\right) .{ }^{25}$ Discrete models were used to reproduce the contact between two different indenters (Berkovich and Vickers) and the sample under analysis. These indenters were modeled as a rigid plate with a triangular and square base, respectively., 19, 26 Samples were modeled using three-dimensional eight-node brick elements, as shown in Figure 2. In these analyses, the pile-up and sink-in defects were disregarded, as well as the friction between the indenter and the sample. ${ }^{4,14,17,27}$ To establish the boundary and geometric conditions of the problem, simplifications were considered to reduce the processing time of these numerical models, as described in the literature and illustrated in Figure 2. ${ }^{4,19}$

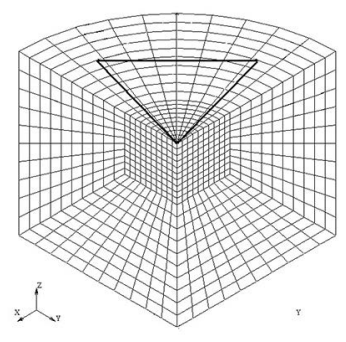

(a)

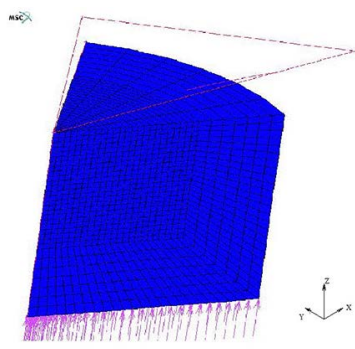

(b)
Figure 2. Illustrations of numerical mesh with isoparametric brick elements (a) for the Vickers model with $1 / 4$ symmetry; and (b) for the Berkovich model with $1 / 6$ symmetry.
The samples studied ( $T i$ substrate and the TiN/Ti system) were modeled as isotropic, homogeneous materials with elastoplastic behavior, described in the literature as the classical expression for strain hardening materials that follows Hollomon's power law relationship., 17-19 The elastoplastic behavior was rewritten as per Equation (1), and the expression used in the finite elements program (Marc $^{\mathrm{TM}}$ 2017). ${ }^{25}$ In this equation, $\sigma$ and $\varepsilon$ are effective stress and strain, respectively, $E$ the elastic modulus, $K$ a constant that describes the hardening characteristics of the material, and $n$ the hardening coefficient. ${ }^{17-19,26-27}$

$$
\sigma=\left\{\begin{array}{l}
E \varepsilon^{1.0}(\text { elastic phase }) \\
K \varepsilon^{n}(\text { plastic phase })
\end{array}\right.
$$

In order to identify the mechanical properties defined in Equation 1, an experimental stage was performed followed by numerical simulation of the indentation test in samples of the substrate $(T i)$ and the film/substrate system (TiN/Ti). Instrumented indentation tests were conducted with a Berkovich penetrator in samples of titanium and the TiN/Ti system. The aim of these tests was to determine the mechanical properties of both the film $(T i N)$ and substrate $(T i)$, using the methodology developed by Dias and Godoy (2010). ${ }^{4}$

Next, the experimental results obtained by Braz et al (2012) were incorporated into the present study. ${ }^{20}$ These authors carried out instrumented indentation tests with a Vickers penetrator in samples of a similar TiN/Ti system, obtaining a surface Vickers hardness curve $\left(H_{I V}\right)$ as a function of maximum penetration depth $\left(h_{\max }\right)$ (Figure 3$){ }^{20}$

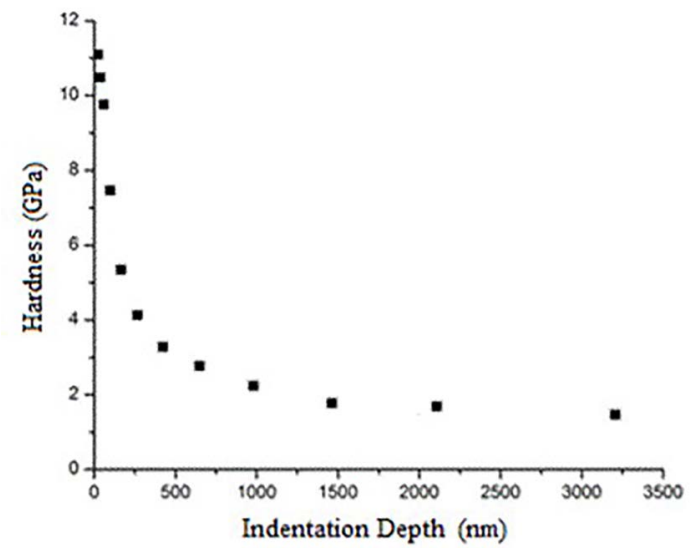

Figure 3. Experimental results for instrumented Vickers hardness as a function of $h_{\max }$ for the $T i / T i N$ system. ${ }^{(20)}$

They determined hardness by considering the true contact area $(A c)$ for the Vickers indenter (Equation 2). ${ }^{20,28}$ In this expression, $P$ is the indentation load, and $H_{I V}$ the instrumented Vickers hardness.

$$
H_{N}=P / A c
$$


A statistical analysis program was used to obtain the experimental instrumented Vickers hardness curve as a function of penetration depth $\left(h_{\max }\right)$, Figure $3 .{ }^{29}$ An exponential power curve was generated as per Equation 3, constants $A_{l}$, $A_{2}, b_{1}, b_{2}$ and $H_{I V o}$ being the coefficients of this expression. ${ }^{19}$

$$
H_{I V}=A_{1} e^{-\frac{x}{b_{1}}}+A_{2} e^{-\frac{x}{b_{2}}}+H_{I V o}
$$

After the mechanical properties of the film/substrate were obtained and validated, the Vickers indentation test was simulated in a sample of the TiN/Ti system. Since film thickness was unknown, different meshes of varying film thickness were prepared, as illustrated in Table 1. In the present study, film thickness was between $100 \mathrm{~nm}$ and $8,000 \mathrm{~nm}$, a wider range than that suggested in the literature for TiN films deposited on Ti substrate..$^{9,20-21,30}$

Table 1. Different meshes used during the simulation of instrumented Vickers hardness for the TiN/Ti system.

\begin{tabular}{ccc}
\hline \multirow{2}{*}{ Film thickness $(\mathrm{nm})$} & \multicolumn{2}{c}{ Number of elements } \\
\cline { 2 - 3 } & Substrate $(\mathrm{Ti})$ & Film $(\mathrm{TiN})$ \\
\hline 100 & 6,750 & 840 \\
150 & 6,750 & 630 \\
200 & 6,750 & 840 \\
300 & 6,750 & 1,050 \\
400 & 6,750 & 1,260 \\
600 & 6,642 & 2,104 \\
800 & 6,642 & 2,204 \\
1,000 & 6,642 & 2.208 \\
1,200 & 6,642 & 2,838 \\
1,400 & 6,642 & 3,254 \\
1,600 & 6,642 & 4,308 \\
2,000 & 6,642 & 5,362 \\
2,600 & 6,642 & 5,354 \\
4,000 & 11,475 & 8,100 \\
8,000 & 19,575 & 16,200 \\
\hline
\end{tabular}

From a numerical standpoint, and not knowing film thickness, a different procedure from that applied in the experimental analysis was performed by simulating this test using varying penetration depths in the samples, with thicknesses described in Table 1. Libório et al (2017) also adopted this easy-to-execute numerical procedure. ${ }^{19}$ Thus, Vickers surface hardness behavior (Equation 1), as a function of the ratio between penetration depth and film thickness $\left(h_{\max } / t\right)$, was obtained numerically. That is, for each simulated penetration depth, the numerical Vickers hardness curve as a function of the ratio $\left(h_{\max } / t\right)$ was determined, as depicted in Equation 3.

Next, by equalizing the expression of the experimental curve $\left(H_{I V} x h_{\max }\right)$ with that of the numerical curve $\left(H_{I V} \times h_{\max } / t\right)$, film thickness became the only remaining unknown variable $(t)$.
However, an algorithm was needed to obtain the convergence of this equalization procedure between the numerical and experimental curve. Despite the different convergent algorithms found in the literature, such as the Newton-Raphson method, none ensure convergence or rapid execution. ${ }^{31}$ Thus, considering the existence of a likely range for the film thickness under study, it was decided to estimate an initial penetration depth value $\left(h_{1}\right)$ that would guarantee surface hardness with a value derived from both the film and substrate. Next, using this estimated $h_{l}$, it was calculated the surface hardness of the system from the experimental curve (Figure 3). Surface hardness, in turn, was used to estimate film thickness $\left(t_{1}\right)$, based on the $H_{I V} x h_{I} / t$ numerical curve obtained. A similar procedure was repeated to obtain a second film thickness $\left(t_{2}\right)$. An algorithm based on the secant algorithm method was used to determine the percentage difference between the estimated values, as shown in Equation $4 .^{31}$ In this expression, a maximum difference of $2 \%$ between $\mathrm{t}_{n-1}$ and $t_{n}$ was adopted as convergence parameter. Estimated penetration depth was added in the direction of convergence until film thickness within the limit of Equation 4 was obtained.

Figure 4 illustrates the flowchart of the methodology proposed to assess $T i N$ film thickness using a combination of experimental Vickers instrumented testing and the numerical simulation of the same test.

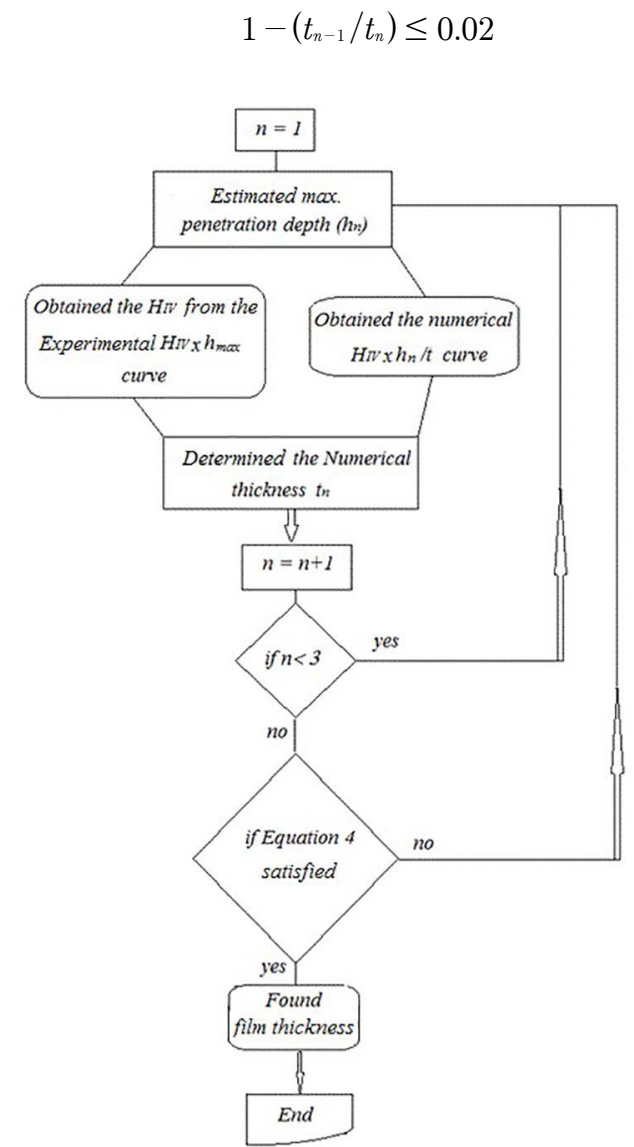

Figure 4. The flowchart used to combine numerical and experimental indentation procedures to determine $T i N$ film thickness. 
According to the literature, the thickness range of a TiN film deposited by similar plasma processing on titanium substrate can vary between $200 \mathrm{~nm}$ and 2,500 nm. ${ }^{9,20-21}$, ${ }^{30}$ Thus, in the present study, a first penetration depth of $1,000 \mathrm{~nm}$ was estimated to obtain experimental hardness, as well as the first numerical hardness curve as a function of the $h_{\max } / t$ ratio to found the first film thickness estimate $\left(t_{l}\right)$, according to the flowchart in Figure 4 . Due to the nonexistence of references for the second penetration depth estimate, the 1,200 $\mathrm{nm}$ and $800 \mathrm{~nm}$ values were tested. Film thicknesses for a greater $\left(h_{1,200}\right)$ and shallower $\left(h_{800}\right)$ depth were obtained, and the difference in $t_{1}$ was determined, using Equation 4. The lowest percentage difference between them would be considered $t_{2}$. It would also indicate the direction for the ensuing increases to reach the percentage difference established in the convergence test $(2 \%)$.

\section{Results and Discussion}

The results of the experimental instrumented Vickers hardness behavior curve as a function of penetration depth for the TiN/Ti system (Figure 3) were analyzed by a statistical program..$^{29}$ As previously discussed, this curve varies from the surface hardness of the film, converging to the surface hardness of the substrate. Table 2 shows the constants for this hardness curve as a function of penetration depth (Figure 3), according to Equation 3.

Table 2. Exponential power curve parameters for experimental hardness behavior as a function of penetration depth.

\begin{tabular}{cccccc}
\hline Constants & $A_{1}$ & $b_{1}$ & $A_{2}$ & $b_{2}$ & $H_{I V 0}$ \\
\hline Values & 9.83 & 122.26 & 1.69 & $1,566.89$ & 1.56 \\
\hline
\end{tabular}

Equation 5 reproduces the exponential curve behavior of Equation 3 with the parameters shown in Table 2. This expression also demonstrates that the experimental surface hardness obtained varies from that of shallow penetration depths (around $13 \mathrm{GPa}$ ), that is, film hardness to substrate hardness for great penetration depths (around 1.56 GPa). The values obtained in Equation 5 were compatible with the range of experimental hardness values of both TiN films and $T i$ substrate. ${ }^{9,21}$ In contrast to the conclusion drawn by Liborio et al (2017), the $H_{I V o}$ constant represents film hardness for great indenter penetration depths, that is, the estimate of this curve for surface substrate hardness. ${ }^{19}$

Table 3 shows the mechanical properties used in the numerical simulation, where the modulus of elasticity $(E)$, Poisson's ratio $(v)$ and yield limit of $T i\left(\sigma_{o}\right)$ were found in the literature. ${ }^{1,32}$ The yield limit of the film $(\mathrm{TiN})$, as well as $K$ and $n$ values for the film and substrate, were obtained from the combination of the experimental result of the Berkovich and numerical tests, in accordance with the methodology developed by Dias and Godoy (2010). ${ }^{4}$

$$
H_{I V}=9.83 e^{-\frac{h_{M A X}}{122.26}}+1.69 e^{-\frac{h_{M A X}}{1,599.89}}+1.56 G P a
$$

Table 3. Mechanical properties of $T i$ and $T i N .^{1,32}$

\begin{tabular}{lccccc}
\hline Material & $K(M P a)$ & $n$ & $\sigma_{0}(M P a)$ & $E(G P a)$ & $v$ \\
\hline Ti & $849.28^{*}$ & $0.012^{*}$ & 799.5 & 120 & 0.3 \\
TiN & $28,115.66^{*}$ & $0.42 *$ & $6,441^{*}$ & 200 & 0.3 \\
\hline
\end{tabular}

*obtained by combining the experimental Berkovich test with numerical simulations (Dias and Godoy 2010). ${ }^{4}$

Table 4 shows a comparison between the results of the experimental Berkovich indentation test for the Ti substrate and the respective numerical values. The experimental procedure involved five to seven tests for each load value selected on the machine, the final result being the mean maximum penetration values $\left(\bar{h}_{\max }\right)$ and maximum indentation load $\left(\bar{P}_{\exp }\right)$. The maximum penetration depth values $\left(h_{n u m}\right)$ used in the numerical simulations were similar to the mean values found in the respective experimental tests. The differences between experimental $\left(P_{\text {exp }}\right)$ and numerical values $\left(P_{\text {num }}\right)$ for maximum indentation load show that the numerical simulation reproduced the overall behavior of Berkovich testing.

Table 4. Comparisons between experimental and numerical results of Berkovich testing.

\begin{tabular}{ccccc}
\hline$h_{\text {num }}(\mathrm{nm})$ & $\bar{h}_{\max }(\mathrm{nm})$ & $\bar{P}_{\text {exp }}(\mathrm{mN})$ & $P_{\text {num }}(\mathrm{mN})$ & Load error \\
\hline 817 & 817 & 26.3 & 24.0 & $9.5 \%$ \\
1,540 & 1,548 & 76.7 & 77.0 & $0.4 \%$ \\
2,170 & 2,154 & 126.7 & 132.7 & $4.7 \%$ \\
4,090 & 4,115 & 507.3 & 518.0 & $2.1 \%$ \\
\hline
\end{tabular}

The comparison between the experimental and numerical values of Berkovich indentation testing was not used for TiN film, given that film thickness was unknown. However, using the expanding cavity model for strain hardening material that follows Hollomon's power law relationship, Gao et al (2006) developed different relationships between Vickers hardness $\left(H_{V}\right)$, yield strength $\left(\sigma_{o}\right)$, the strain-hardening exponent $(n)$, and Young's modulus $(E) .{ }^{33}$ The Vickers hardness calculated from the Gao et al. (2006) formulations was then compared with the values obtained here. ${ }^{33}$ Applying Equation 6, for elastic power-law hardening materials, obtained an estimated Vickers hardness of TiN film and Ti steel substrate (Table 3) of 17.38 $\mathrm{GPa}$ and $2.47 \mathrm{GPa}$ respectively, using their mechanical properties. In this expression, $\alpha$ is the half-included angle of the cone equivalent to the Vickers indenter., ${ }^{6} 19$ The film (TiN) and substrate (Ti) hardness calculated from Equation 6 were very close to previously shown Vickers hardness values. However, these differences could be explained by the fact that Vickers hardness estimated by Equation 6 did not use the true contact area or because Gao et al (2006) formulations are more accurate when applied to bulk materials. ${ }^{19,33}$ 


$$
H_{V}=\frac{2}{3}\left\{\left(1-\frac{1}{n}\right)+\left(\frac{3}{4}+\frac{1}{n}\right)\left(\frac{1}{3} \frac{E}{\sigma_{0}} \cot \alpha\right)^{n}\right\} \sigma_{0}
$$

Figure 5 shows the numerical instrumented Vickers hardness behavior curve as a function of the ratio between depth and penetration film thickness $\left(h_{\max } / t\right)$ for the system under study (TiN/Ti). As described in Methodology, this first numerical curve considered the $1,000 \mathrm{~nm}$ maximum penetration depth. Table 5 shows the constant values of this numerical curve. Equation 7 rewrote the behavior of the Equation 3 power law curve with the parameters shown in Table 5.

$$
H_{I V}=6.77 e^{-\frac{1,000 / t}{0.42}}+0.73 e^{-\frac{1,000 / t}{2.80}}+1.36 \mathrm{GPa}
$$

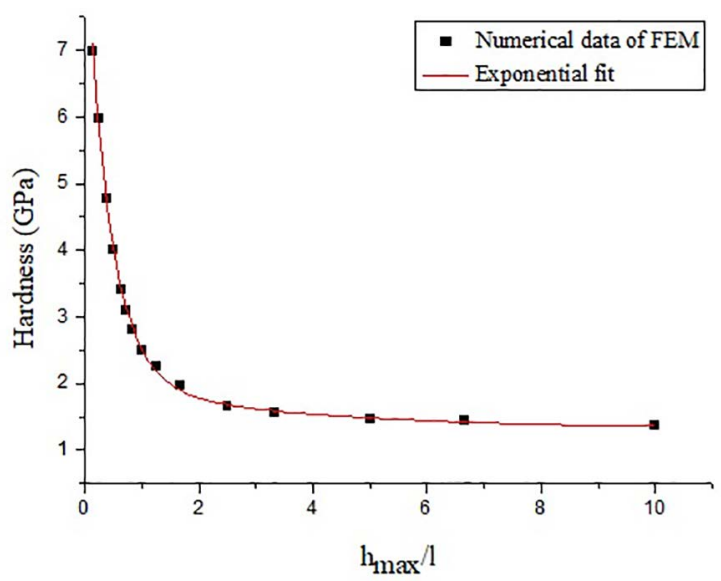

Figure 5. Numerical results for Vickers indentation hardness as a function of $h_{\max } / l$ for the Ti/TiN system considering a $1,000 \mathrm{~nm}$ penetration depth.

Table 5. Exponential power curve parameters for numerical hardness behavior as a function of ratio $h_{\max } / t$.

\begin{tabular}{ccccccc}
\hline Constants & $A_{1}$ & $b_{1}$ & $A_{2}$ & $b_{2}$ & $H_{I V_{0}}$ & $h_{\max }$ \\
\hline Values & 6.77 & 0.42 & 0.73 & 2.80 & 1.36 & $1,000 \mathrm{~nm}$ \\
\hline
\end{tabular}

The behavior of this numerical hardness curve is qualitatively compatible with the experimental behavior shown in Figure 3. For example, the numerical result shows that the hardness obtained for high penetration depths (high $h_{\max } / t$ ratio) was around 1.36 GPa (substrate hardness). This value was close to the experimental surface hardness value of the substrate obtained by Equation 5 (1.56 GPa).
Considering the stages described in the flowchart of Figure 4, after the numerical curve of $H_{I V} \times h_{\max } / t$ (Figure 5) was obtained for a penetration depth of 1,000 $\mathrm{nm}$, an experimental hardness value of $2.47 \mathrm{GPa}$ was determined by Equation 5 for $h=1,000 \mathrm{~nm}$. This surface hardness value was applied to the expression of the numerical curve described in Figure 5, resulting in a film thickness estimate of $978.3 \mathrm{~nm}\left(t_{1}\right)$. As described earlier, the same procedure was applied to two other penetration depths $\left[\left(800 \mathrm{~nm}\left(h_{800}\right)\right.\right.$ and 1,200 $\left.\mathrm{nm}\left(h_{1,200}\right)\right]$. Table 6 shows the estimated surface hardness and film thickness results for these three penetration depths. The lowest percentage difference was between $978.3 \mathrm{~nm}$ and $1,112.2 \mathrm{~nm}(12 \%)$, with the latter considered $t_{2}$

Table 6. Comparison between numerical hardness obtained from initial penetration depth estimates.

\begin{tabular}{cccc}
\hline Numerical power law curve & \multicolumn{3}{c}{ Penetration depth } \\
\cline { 2 - 4 } parameters (Equation 3) & $800 \mathrm{~nm}$ & $1,000 \mathrm{~nm}$ & $1,200 \mathrm{~nm}$ \\
\hline$A_{I}$ & 0.75019 & 6.77274 & 1.19470 \\
$b_{1}$ & 12.45042 & 0.42195 & 1.84644 \\
$A_{2}$ & 6.87972 & 0.73123 & 6.62984 \\
$b_{2}$ & 0.46992 & 2.79706 & 0.35447 \\
$H_{I V_{0}}$ & 1.00618 & 1.36140 & 1.37881 \\
Numerical $H_{I V}(\mathrm{GPa})$ & 2.602 & 2.470 & 2.361 \\
Numerical film thickness $(\mathrm{nm})$ & 837.31 & 978.30 & $1,112.22$ \\
Error & $21.189 \%$ & $14.411 \%$ & $12.041 \%$ \\
\hline
\end{tabular}

Next, a penetration depth of $1,400 \mathrm{~nm}$ was used until a difference of less than $2 \%$ was achieved, according to the convergence test of Equation 4. Table 7 shows the results obtained for estimated penetration depth using the numerical-experimental algorithm developed in the present study. Finally, the estimated film thickness of the system analyzed was around 1,292 nm, which is within expected values for a similar system investigated by different authors. ${ }^{9,}$ 19-21, 30

Unfortunately, it was impossible to determine the experimental film thickness of the system under study due to the need for specific instruments and costly, time-consuming tests such as scanning electron microscopy (SEM) and atomic force microscopy (AFM). ${ }^{19}$

Table 7. Determination of film thickness using the convergence criterion described in the flow chart of Figure 4.

\begin{tabular}{cccccc}
\hline Numerical results & \multicolumn{5}{c}{ Penetration depth } \\
\cline { 2 - 5 } & $1,000 \mathrm{~nm}$ & $1,200 \mathrm{~nm}$ & $1,400 \mathrm{~nm}$ & $1,450 \mathrm{~nm}$ & $1,475 \mathrm{~nm}$ \\
\hline$H I V(G P a)$ & 2.47 & 2.36 & 2.27 & 2.25 & 2.23 \\
Film thickness $(\mathrm{nm})$ & 978.30 & $1,112.22$ & $1,225.22$ & $1,272.14$ & $1,291.63$ \\
Error & $14.411 \%$ & $12.041 \%$ & $9.223 \%$ & $3.688 \%$ & $1.509 \%$ \\
\hline
\end{tabular}




\section{Conclusions}

The numerical model developed here adequately represents the general behavior of the different indentation tests. Moreover, the results obtained for the mechanical properties of the film ( TiN) and substrate (Ti) confirmed the effectiveness of the methodology proposed by Dias and Godoy (2010), reproducing the mechanical behavior of these materials in the simulation of Berkovich indentation testing. ${ }^{4}$

The algorithm proposed to determine the convergence of the numerical and experimental curves proved to be an easy procedure. The technique adopted to estimate film thickness by combining the results of experimental (Figure 3) and numerical (Figure 5) indentation hardness tests produced a film $(T i N)$ thickness within the range of values recommended by the literature. This procedure proved to be a low-cost methodology to determine the thickness of plasma-processed TiNfilms on metallic substrates, when compared to experimental procedures such as scanning electron microscopy (SEM) and atomic force microscopy (AFM).

In order to improve this methodology in future research, it is suggested that the experimental numerical behavior of Berkovich hardness be compared, given that this experimental testing was conducted a priori to determine the mechanical properties of the TiN/Ti system required for numerical simulation. Finally, the numerical model could be enhanced by simulating extremely thin, multilayered films and incorporating the analysis of anisotropic and non-homogeneous films into these studies.

\section{Acknowledgments}

The authors gratefully acknowledge the funding by CNPq (Brazilian Council for Scientific and Technological Development), through protocol numbers 484818/20112 and 460943/2014-6. The first author also thanks the financial support provided by CAPES (Coordination for the Improvement of Higher Education Personnel), through protocol number BEX 6569-14.

\section{References}

1. Shan Z, Sitaraman SK. Elastic-plastic characterization of thin films using nanoindentation technique. Thin Solid Films. 2003;437(1-2):176-181.

2. Fischer-Cripps AC. Critical review of analysis and interpretation of nanoindentation test data. Surface and Coatings Technology. 2006;200:4153-4165.

3. Liao Y, Zhou Y, Huang Y, Jiang L. Measuring elastic-plastic properties of thin films on elasticplastic substrates by sharp indentation. Mechanics of Materials. 2009;41(3):308-318.

4. Dias AMS, Godoy GCD. Determination of StressStrain Curve through Berkovich Indentation Testing. Materials Science Forum. 2010;636-637:1186-1193.
5. Pulécio SAR, Farias MCM, Souza RM. Finite element and dimensional analysis algorithm for the prediction of mechanical properties of bulk materials and thin films. Surface and Coatings Technology. 2010;205(5):1386-1392.

6. Moussa C, Bartier O, Mauvoisin G, Pilvin P, Delattre G. Characterization of homogenous and plastically graded materials with spherical indentation and inverse analysis. Journal of Materials Research. 2012;27(1):20-27.

7. Hemmouche L, Chicot D, Amrouche A, Iost A, Belouchrani MA, Decoopman X, et al. An analysis of the elastic properties of a porous aluminium oxide film by means of indentation techniques. Materials Science and Engineering: A. 2013;585:155-164.

8. Yetna N'Jock M, Chicot D, Decoopman X, Lesage J, Ndjaka JM, Pertuz A. Mechanical tensile properties by spherical macroindentation using an indentation strain-hardening exponent. International Journal of Mechanical Sciences. 2013;75:257-264.

9. Azadi M, Rouhaghdam AS, Ahangarani S. Mechanical Behavior of TiN/TiC-n Multilayer Coatings and Ti(C,N) Multicomponent Coatings Produced by PACVD. Strength of Materials. 2016;48(2):279-289.

10. Bressan JD, Tramontin A, Rosa C. Modeling of nanoindentation of bulk and thin film by finite element method. Wear. 2005;258(1-4):115-122.

11. de Souza GB, Foerster CE, da Silva SLR, Serbena FC, Lepienski CM, dos Santos CA. Hardness and elastic modulus of ion-nitrided titanium obtained by nanoindentation. Surface and Coatings Technology. 2005;191(1):76-82.

12. Vanimisetti SK, Narasimhan R. A numerical analysis of spherical indentation response of thin hard films on soft substrates. International Journal of Solids and Structures. 2006;43(20):6180-6193.

13. Mady CEK, Rodriguez SA, Gómez AG, Souza RM. Numerical analysis of different methods to calculate residual stresses in thin films based on instrumented indentation data. Journal of Materials Research. 2012;27(13):1732-1741. DOI: http:// dx.doi.org/10.1557/jmr.2012.166

14. Rodriguez SAR, Alcalá J, Souza RM. The reduced modulus in the analysis of sharp instrumented indentation tests. Journal of Materials Research. 2012;27(16):2148-2160.

15. ReccoAAC, Tschiptschin AP. Structural and Mechanical Characterization of Duplex Multilayer Coatings Deposited onto H13 Tool Steel. Journal of Materials Research and Technology. 2012;1(3):182-188.

16. Wang D, Zhao J, Li A, Cui X, Chen X. Microstructure level modelling for properties prediction of WC-Co cemented carbides. Materials Research Innovations. 2013;17(Suppl 2):40-45. DOI: http://dx.doi.org/1 $0.1179 / 1432891713 Z .000000000311$ 
17. Araújo R, Dias AMS. Numerical Evaluation of Strength in the Interface during Indentation Spherical Testing in Thin Films. Materials Science and Applications. 2014;5(3):149-157. DOI: http:// dx.doi.org/10.4236/msa.2014.53019

18. Fukumasu NK, Souza RM. Numerical evaluation of cohesive and adhesive failure modes during the indentation of coated systems with compliant substrates. Surface and Coatings Technology. 2014;260:266-271. DOI: http://dx.doi.org/10.1016/j. surfcoat.2014.07.093

19. Libório MS, Dias AMS, Souza RM. Determination of Film Thickness through Simulation of Vickers Hardness Testing. Materials Research. 2017;20(3):755-760.

20. Braz DC, Barbosa JCP, Nunes Filho A, Rocha RCS, Silva DR, Alves Jr C. Influence of plasma species on the surface properties modification of titanium treated with a $\mathrm{N}_{2}-\mathrm{Ar}_{-} \mathrm{O}_{2}$ plasma. Matéria (Rio de Janeiro). 2012;17(2):1035-1044.

21. Nunes Filho A, Braz DC, Hinrichs R, Vasconcellos MAZ, Rocha RCS, Alves Jr C. Influence of the emission patterns of species in a carbonitriding plasma on the surface properties of TiCN. Matéria (Rio de Janeiro). 2015;20(1):72-82.

22. Godoy C, Mancosu RD, Machado RR, Modenesi PJ, Avelar-Batista JC. Which hardness (nano or macrohardness) should be evaluated in cavitation? Tribology International. 2009;42(7):1021-1028. DOI: $10.1016 /$ j.triboint.2008.09.007

23. Oliver WC, Pharr GM. Measurement of hardness and elastic modulus by instrumented indentation: Advances in understanding and refinements to methodology. Journal of Materials Research. 2004;19(1):3-20.
24. Le Bourhis E. Indentation mechanics and its application to thin film characterization. Vacuum. 2008;82(12):1353-1359.

25. MSC Software. MARC. Volume A: Theory and User Information, Users Manual; 2017. Available from: $<$ https://mscsoftware.com>. Access in: 31/10/2017.

26. Dias AMS, Modenesi PJ, de Godoy GC. Computer simulation of stress distribution during Vickers hardness testing of WC-6Co. Materials Research. 2006;9(1):73-76. DOI: http://dx.doi.org/10.1590/ S1516-14392006000100014

27. Vedaei-Sabegh A, Ahmadi SR, Gholamzadeh B. Investigation of pile-up during a rigid ball sliding on coated surface based on elastic-plastic analysis. Surface and Coatings Technology. 2014;251:283-292.

28. Chicot D, Tricoteaux A. Mechanical Properties of Ceramics by Indentation: Principle and Applications. In: Wunderlich W, ed. Ceramic Materials. Chapter 7. London: IntechOpen; 2010.

29. OriginLab Corporation. OriginPro; 2015. Available from: $<$ http://www.originlab.com $>$. Access in 09/2017.

30. da Silva SS, Bottoni CR, Gontijo LC, Ferreira SO. Plasma deposition of titanium nitride thin films under the effect of hollow cathode length in cathodic cage. Matéria (Rio de Janeiro). 2017;22(3):e11857. DOI: http://dx.doi.org/10.1590/S1517-707620170003.0191

31. Press WH, Teukolsky SA, Vetterling WT, Flannery BP. Numerical Recipes: The Art of Scientific Computing. $3^{\text {rd }}$ ed. Cambridge: Cambridge University Press; 2007.

32. Matweb. Material Property Data. Available from: $<$ http://www.matweb.com>. Access in: 11/2017.

33. Gao XL, Jing XN, Subhash G. Two new expanding cavity models for indentation deformations of elastic strain-hardening materials. International Journal of Solids and Structures. 2006;43(7-8):2193-2208. 